\title{
Vein Immunoglobulin Therapy may Induce Pancreatic Damage in Myasthenic Patients: A Case Report
}

Gaetano Gorgone ${ }^{1 *}$, Carmen Colica ${ }^{2}$, Massimiliano Plastino ${ }^{1}$, Antonietta Fava ${ }^{3}$, Dario Cristiano ${ }^{1}$, Demetrio Messina ${ }^{1}$, Alessandra Fratto ${ }^{1}$ and Domenico Bosco ${ }^{1}$

${ }^{1}$ Department of Neuroscience, "S. Giovanni di Dio" Hospital, Largo Bologna, 88900, Crotone, Italy

${ }^{2}$ Institute of Neurological Science - National Research Council, UVS-IBFN, 88100 - Catanzaro, Italy

${ }^{3}$ Department of Clinical and Experimental Medicine, University of Catanzaro, 88100 - Catanzaro, Italy

Correspondence to:

Gaetano Gorgone, $\mathrm{MD}, \mathrm{PhD}$

Department of Neuroscience

"S. Giovanni di Dio" Hospital

Largo Bologna, 88900, Crotone, Italy

Tel: +390962924241

Fax: +390962924561

E-mail: gaegorg@alice.it

Received: November 27, 2016

Accepted: February 20, 2017

Published: February 22, 2017

Citation: Gorgone G, Colica C, Plastino M, Fava A, Cristiano D, et al. 2017. Vein Immunoglobulin Therapy may Induce Pancreatic Damage in Myasthenic Patients: A Case Report. J Neurol Exp Neurosci 3(1): 8-10.

Copyright: (C) 2017 Gorgone et al. This is an Open Access article distributed under the terms of the Creative Commons Attribution 4.0 International License (CC-BY) (http://creativecommons. org/licenses/by/4.0/) which permits commercial use, including reproduction, adaptation, and distribution of the article provided the original author and source are credited.

Published by United Scientific Group

\section{Abstract}

Background: Myasthenia gravis (MG) is an autoimmune neurological disease characterized by fluctuating fatigable skeletal muscle weakness that represents a challenge for physicians due to the diversity of the disease manifestations and the possibility of fatal complications.

Case report: We report the case of a 45-year-old female patient with myasthenia gravis, who developed reversible signs of pancreatic damage, probably related to immunoglobulin vein infusion therapy (IGiv). During this treatment, the patients had an increase of the serum pancreatic enzymes, greater than five times the upper limit of normal values, resolved, without treatment, after the suspension of IGiv. Moreover, a magnetic resonance with cholangiography, showed a slight hyperintensity of the head of the pancreas.

Conclusions: The close temporal relationship between the vein infusion of immunoglobulin and the increase of serum pancreatic enzymes in our patient suggests that IGiv may have a toxic effect on the pancreatic cells that disappears with the suspension of IGiv.

\section{Keywords}

Myasthenia gravis, Immunoglobulin vein infusion, Pancreatic damage, Reversible reaction, Temporal relation, Enzymes increase

\section{Introduction}

Myasthenia gravis (MG) is an autoimmune neurological disease mediated by immunoglobulin $G$ autoantibodies to components of the postsynaptic neuromuscular junction (NMJ), characterized by fluctuating fatigable skeletal muscle weakness [1]. It represents a challenge for physicians due to the diversity of disease manifestations and possibility of respiratory complications. Worsening of myasthenic symptoms often requires hospitalization of the patients and plasma exchange therapy and IGiv may represent a choice in the acute management of this neuromuscular junction disease. We report the case of 45-year-old female patient with myasthenia gravis who developed laboratory signs of pancreatitis during the IGiv therapy.

\section{Case Report}

A 45-year-old woman with an history of myasthenia gravis, arrived at the emergency department with symptoms of dysphagia for liquids and solids, from 
two months. She also reported complaints of dysphonia from two weeks. Both symptoms worsened during the day. Physical examination on admission revealed complete eye movements without diplopia in the tests of fatigue, symmetric facial movements, tongue protrusion in the midline and symmetrical vocal folds, with no lesions, while, a difficult in the elevation of the soft palate, and a slight palpebral ptosis, in the left eye were found. Remaining neurological examination also revealed a slight weakness of the proximal limbs muscles. Standard hematological tests and blood chemistries (complete blood count differential, platelet count, electrolytes, serum creatinine, liver and pancreatic enzymes, uric acid, thyroid function, cyanocobalamin and folic acid plasma levels) were normal. A nasogastric tube was placed to prevent pneumonia inhalation and, a femoral vein cannulation was required, in order to perform a plasma exchange therapy.

An iatrogenic left femoral artery injury due to the central venous catheter placement did not permit to perform the plasma exchange therapy and, the patient underwent vascular cover stenting. Subsequently, CT-scan of abdomen was performed and the presence of an active bleeding, was mandatory for a surgical hemostasis of the left iliac artery and of the Gerota's fascia veins. In the following days, the patient was moved to the intensive-care unit and a IGiv treatment (Venital, $2.4 \mathrm{~g} / \mathrm{kg}$, administered over six days) plus steroid therapy (IV dexamethasone, gradually increased at the dose of $14 \mathrm{mg}$ daily) and oral pyridostigmine $(60 \mathrm{mg}$ 4-times a day) has been initiated, with a partial improvement of the proximal limbs weakness. Before the IGiv therapy initiation, serum immunoglobulin levels were within the normal values. In particular total IgG-antibodies were $1050 \mathrm{mg} / \mathrm{dL}$ (normal value of our laboratory $695-1750 \mathrm{mg} / \mathrm{dL}$ ). Seven days after, the patients was admitted to our neurological department to continue medical treatment. An additional IGiv immunomodulatory therapy was begun (Venital, $2.0 \mathrm{~g} / \mathrm{kg}$, administered over five days), maintaining steroid treatment and oral pyridostigmine. The IGiv therapy was discontinued three days after, due to an increase of the pancreatic enzymes, greater than six times the upper limit of normal values, together with slight increase of total serum IgG-antibodies levels, above the normal ranges of our laboratory $(1955 \mathrm{mg} / \mathrm{dL})$.

This laboratory abnormalities resolved, without treatment, five day after the discontinuation of IGiv. One month later, the patient underwent a new high-dosage IGiv therapy cycle (Venital, $2.0 \mathrm{~g} / \mathrm{kg}$, administered over five days), because the worsening of dysphagic symptoms: again, the pancreatic enzymes raised more than five times the upper limit of normal values and, then, decreased few days after the discontinuation of the IGiv. Clinical examination was negative, while an abdominal magnetic resonance with cholangiography evidenced a slight hyper-intensity of the pancreatic head. Once Again, an increase of total serum IgG-antibodies levels, above the normal ranges of our laboratory $(1857 \mathrm{mg} / \mathrm{dL})$ was found in our patient.

\section{Discussion}

Our patient had an increase of pancreatic enzyme plasma levels, occurred during IGiv and that disappeared, when this treatment was stopped. To our knowledge this is the first report of an increase of pancreatic enzymes related to IGiv therapy. Although there are no available data supporting this causal association, our observation suggests a possible link, corroborated by the presence of a temporal relation between IGiv and increase of pancreatic enzymes, which has been resolved, without any specific treatment, after the discontinuation of $\mathrm{IGiV}$. Moreover, our patient was treated with high dosage of IGiv, that probably contributed to an accumulation of $\mathrm{IgG}$-antibodies, due to a decreased intracellular catabolism of them. It is widely reported, that antibodies metabolism mainly occurs via fluid-phase endocytosis, or through the interaction of the Fab binding domains of the antibody, with the cell surfaces target epitopes [2]. This type of elimination is, by definition, capacity- limited (saturable), and represents a significant contributor to the kinetics of antibodies distribution and elimination [2].

Another possible determinant in the catabolism of IGiV may be represented by the lymphatic system capability to remove the macromolecules from the extracellular tissue's compartment [3]. In our patient an iatrogenic abdominal bleeding was mandatory for vascular surgery of left Gerota's fascia veins, that if damaged, may induce a condition of lymphatic congestion, with a possible accumulation of cellular catabolism products and the activation of various lymphatic/endothelial immune mediating signaling pathways [4]. Thus, it is possible that, in our case, the high dosage therapeutic IGiv regimen, together with an altered kinetics of the receptor mediated - endocytosis, and a local lymphatic vessels congestion may lead the pancreatic damage, through several mechanisms, including inducible nitric oxide synthaseexpressing, and decreased migration of the macrophages within the lymphatics [5]. Subsequently, B cells in the draining lymph nodes, may translocate from the follicles to the paracortical sinuses, via a yet to be determined mechanism, clogging the afferent lymphatics and triggering pancreatic damage. Interestingly, that alterations of receptor-mediated endocytosis and of lymphatic flow have been identified in several autoimmune diseases such as, chronic autoimmune pancreatitis [6], rheumatoid arthritis [7], while, specific IgG4 antibodies have been strongly implicated in mediating diseases such as pemphigus foliaceus [8] and some cases of membranous glomerulonephritis [8].

In conclusion, our patient shows characteristics which have never been reported. An accumulation of similar cases may prompt us to better understand the safety's profile of IGiv therapy in neurological autoimmune diseases.

\section{Acknowledgements}

The authors have no conflict of interest to disclose. None of the authors have received financial support or funding for the research covered in this article.

\section{References}

1. Drachman DB. 1994. Myasthenia gravis. NEngl J Med 330(25): 17971810. https://doi.org/10.1056/NEJM199406233302507 
2. Lobo ED, Hansen RJ, Balthasar JP. 2004. Antibody pharmacokinetics and pharmacodynamics. J Pharm Sci 93(11): 2645-2668. https://doi. org/10.1002/jps.20178

3. Wang W, Wang EQ, Balthasar JP. 2008. Monoclonal antibody pharmacokinetics and pharmacodynamics. Clin Pharmacol Ther 84(5): 548-558. https://doi.org/10.1038/clpt.2008.170

4. Dieterich LC, Seidel CD, Detmar M. 2014. Lymphatic vessels: new targets for the treatment of inflammatory diseases. Angiogenesis 17(2): 359-371. https://doi.org/10.1007/s10456-013-9406-1

5. Scallan JP, Davis MJ. 2013. Genetic removal of basal nitric oxide enhances contractile activity in isolated murine collecting lymphatic vessels. J Physiol 591(8): 2139-2156. https://doi.org/10.1113/ jphysiol.2012.250662

6. Ketwaroo GA, Sheth S. 2013. Autoimmune pancreatitis. Gastroenterol Rep 1(1): 27-32. https://doi.org/10.1093/gastro/got011

7. Liang Q,Ju Y, Chen Y, Wang W, Li J, et al. 2016. Lymphatic endothelial cells efferent to inflamed joints produce iNOS and inhibit lymphatic vessel contraction and drainage in TNF-induced arthritis in mice. Arthritis Res Ther 18: 62. https://doi.org/10.1186/s13075-016-0963-8

8. Rock B, Martins CR, Theofilopoulos AN, Balderas RS, Anhalt GJ, et al. 1989. The pathogenic effect of IgG4 autoantibodies in endemic pemphigus foliaceus (fogo selvagem). N Engl J Med 320(22): 14631469. https://doi.org/10.1056/NEJM198906013202206 